\title{
Occurrence of Echinococcus spp. in red foxes and wolves in the protected area of the Tatra National Park in southern Poland - a threat to human health
}

\author{
Jakub Gawor, ${ }^{1, A-B, D-E \oplus}$, Zdzisław Laskowski ${ }^{1, A, C, E-F \oplus}{ }^{\circ}$, Anna W. Myczka ${ }^{1, C, E \oplus}$, \\ Tomasz Zwijacz-Kozica ${ }^{2, B, E-F}{ }^{(0)}$, Rusłan Sałamatin ${ }^{3,4, B-C(D)}$ \\ ${ }^{1}$ W. Stefański Institute of Parasitology of the Polish Academy of Sciences, Warsaw, Poland \\ 2 Tatra National Park, Poland \\ ${ }^{3}$ Department of General Biology and Parasitology, Medical University of Warsaw, Warsaw, Poland \\ ${ }^{4}$ Faculty of Medicine, Collegium Medicum, Cardinal Stefan Wyszyński University in Warsaw, Warsaw, Poland \\ A - Research concept and design, B - Collection and/or assembly of data, C - Data analysis and interpretation, \\ $D$ - Writing the article, E - Critical revision of the article, F - Final approval of article
}

Gawor J, Laskowski Z, Myczka AW, Zwijacz-Kozica A, Sałamatin R. Occurrence of Echinococcus spp. in red foxes and wolves in the protected area of the Tatra National Park in southern Poland - a threat to human health. Ann Agric Environ Med. $2021 ; 28(4)$ : 579-584. doi: 10.26444/aaem/131649

\begin{abstract}
Introduction. Echinococcus multilocularis has been endemic in red foxes in eastern and central parts of Europe, and E. granulosus s. I. identified in wolves in some countries. In recent years, wolves hale emerged as potentially important definitive hosts of E. multilocularis.

Objective. This aim of the survey was to record indirectly using nested-PCR test with faecal samples the presence of Echinococcus multilocularis and E. granulosus s. I. in the two species of wild canids in the protected area of the Tatra National Park (TNP) in Western Carpathian, southern mountainous part of Poland.

Materials and method. From February to June 2019, experienced staff of TNP randomly collected fox and wolf faeces on and off hiking trails at altitudes from $850 \mathrm{~m}$ to 2,000 m above sea level. In total, 91 faecal samples from red foxes and 19 from wolves were collected. Genomic DNA was obtained by direct extraction from faecal samples using a commercial kit, and from taeniid eggs retrieved from the same samples after flotation.

Results. A nested PCR screening of 91 red fox faeces indicated the prevalence of $E$. multilocularis of $4.4 \%$. Positive samples were confirmed by sequencing parts of the mitochondrial cytochrome $c$ oxidase subunit 1 gene (cox 1$)$. Neither genomic DNA of E. multilocularis nor of E. granulosus s.l. was obtained from 19 wolves faeces, nor from taeniid eggs retrieved from these samples by initial flotation.

Conclusions. The current results show that humans might be exposed to a risk of fox tapeworm infection in nature, even at high altitude inan alpine zone, in an environment contaminated by roaming red foxes encouraged by food leftovers on mountain trails.
\end{abstract}

\section{- Key words}

Echinococcus multilocularis, E. granulosus, red fox, wolf, PCR, cox1

\section{INTRODUCTION}

In Europe, Echinococcus spp. are represented by two species of small tapeworms, E. multilocularis, with a sylvatic life cycle between canids, particularly the red fox (Vulpes vulpes) and microtine rodents, and E. granulosus sensu lato which is transmitted mainly between dogs and ungulates. Echinococcus multilocularis has been endemic in Eastern and Central parts of Europe $[1,2,3,4,5]$. During the past decades, the known geographic distribution of E. multilocularis in red foxes has been expanding east and north from its endemic areas in Central Europe $[1,6,7,8]$. In the last few years, an extension of the southern boundary of the endemic areas has been reported $[9,10,11]$. The parasite's expansion southward has been revealed in wolves (Canis lupus) in the Southern Italian Alps

Address for correspondence: Jakub Gawor, W. Stefański Institute of Parasitology of the Polish Academy of Sciences, Twarda 51/55, 00-818 Warsaw, Poland E-mail: gaworj@twarda.pan.pl

Received: 07.10.2020; accepted: 08.12.2020; first published: 30.12 .2020
[11] and in golden jackals (Canis aureus) in parts of the Balkan peninsula, i.e. in Serbia and Croatia $[10,12]$. A preliminary ranking of E. multilocularis infection in red foxes in Europe, based on pooled prevalence, identified Poland among the high prevalence territories with a pooled prevalence of $>10 \%$ [7]. In some provinces and districts of eastern and southern Poland, the tapeworm was recorded in $47.2 \%-63.9 \%$ of foxes $[3,13,14]$. Echinococcus granulosus sensu lato has a global distribution, and in Europe this complex species circulates mainly as $E$. granulosus sensu stricto genotype (G1 'sheep strain'), and to a lesser extent, in Central and Eastern Europe as E. canadensis (G7 'pig strain'). In Poland, the presence of E. canadensis and E. granulosus s.s. was confirmed in hydatid cysts collected from humans, pigs and sheep [15]. Both Echinococcus species are zoonotic. Human exposure to the tapeworms eggs in the environment contaminated by faeces of infected canids can result in a larval metacestode forming in the body, usually in the liver, causing alveolar echinococcosis or larval cyst in the liver and body cavity, causing cystic echinococcosis. 


\section{OBJECTIVES}

The aim of this study was to evaluate Echinococcus multilocularis and E. granulosus s.l. infection in red foxes (Vulpes vulpes) and grey wolves (Canis lupus) living in the Tatra National Park in the western part of the Carpathians in southern Poland. The investigations were based on molecular identification with direct extraction of parasites DNA from faeces and from taeniid eggs retrieved by flotation.

\section{MATERIALS AND METHOD}

Study area. In the present study, faecal material was collected from red foxes and wolves in Tatra National Park (Western Carpathians) in southern Poland at the border with Slovakia (Fig. 1). The protected area covers $212 \mathrm{~km}^{2}$ and is surrounded by a diverse environment including fields and forests, as well as dense settlements. Landscapes are different with slopes, rocks and alpine zones, with elevation between 800 and $2495 \mathrm{~m}$ above sea level. The protected area is inhabited by 14 wolves, according to genetic investigation [16], and approximately 50 red foxes, as estimated by rangers [17]. Because the National Park is visited each year by approximately 3 million tourists and is surrounded by dense settlements, the appearance of infected wild canids is a major concern.
Faecal samples and flotation analysis. From February to June 2019, experienced staff of the Tatra National Park (TNP) randomly collected fox and wolf faeces within the park limits. The samples were collected on and off hiking trails by rangers while patrolling the national park area, at altitudes from $850 \mathrm{~m}-2000$ above sea level. In total, 91 faecal samples from red foxes and 19 from wolves were collected. Only fresh faeces, with a visible mucus layer were collected. Faeces of foxes are often seen on popular hiking trails, as they use them looking for human food leftovers, even if this is not very important part of fox diet in the Tatra National Park [18]. Wolf faeces were collected during snow tracking. In a few cases, fox and wolf faeces was collected at remains of their prey, mostly wolf prey although used also by foxes.

Until analysis by flotation and molecular examination were performed, the samples were maintained frozen at $-80^{\circ} \mathrm{C}$ for two weeks for decontamination [19]. Flotation with sodium chloride / sugar (sucrose) saturated solution (1.28 specific gravity) [20] was performed to recover taeniid eggs from fox and wolf faeces. The flotation was repeated for each positive sample to retrieve eggs for molecular analysis, and $100 \mu \mathrm{l}$ of each supernatant with eggs was subjected for testing by PCR.

Molecular procedures - PCR optimization. Taking into account the specificity of the studied material, i.e. the method of collecting, transporting and thawing the faecal samples and the possibility of DNA degradation in the

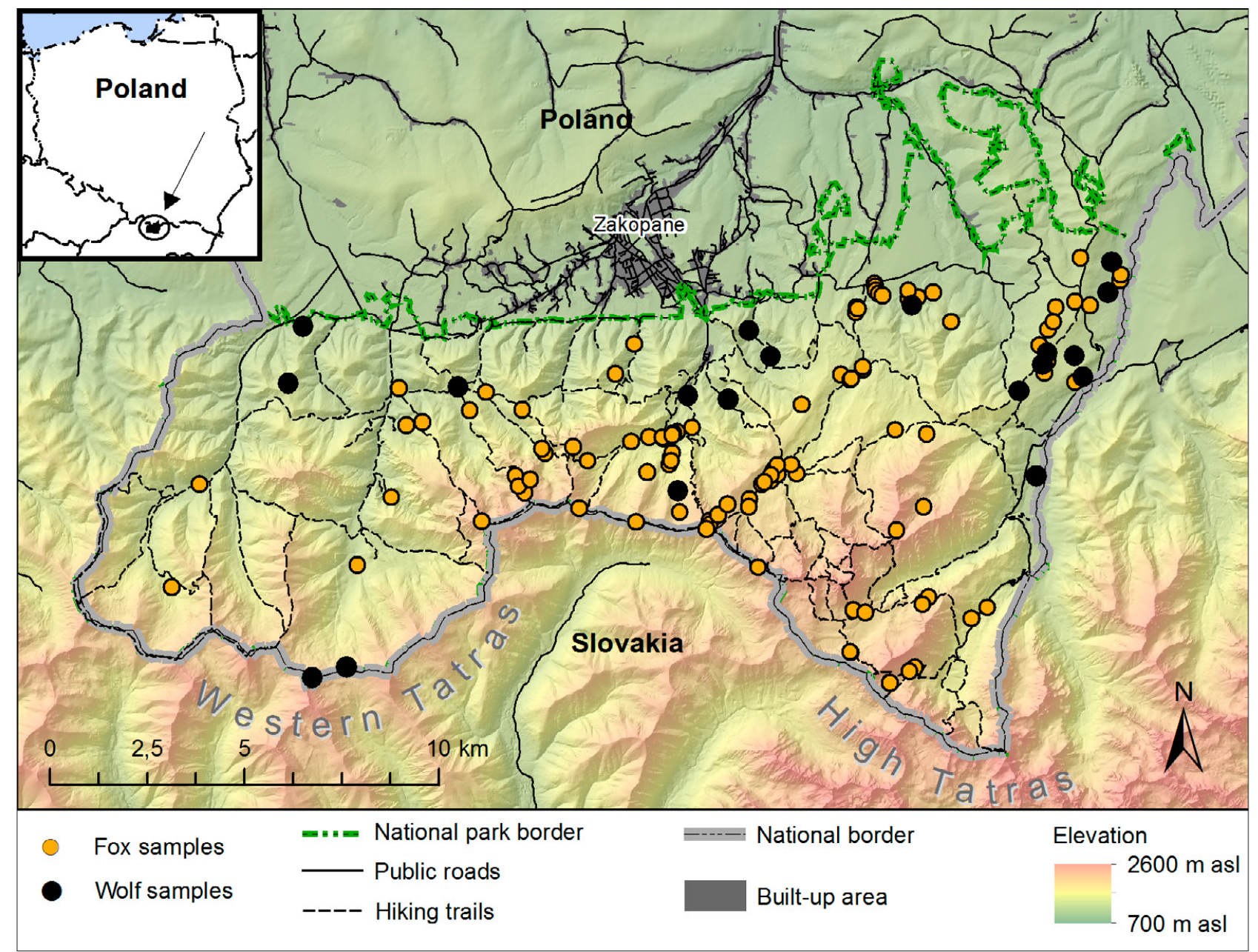

Figure 1. Study area - red fox and wolf faecal samples collection 
tested samples, a set of PCR reaction primers, designed for amplification of a short fragment of the mitochondrial gene coding cytochrome $c$ subunit 1, specific for E. multilocularis and E. granulosus s.s. (G1) was designed (GenBank accessions numbers: AB461413 and MH686292, respectively). For amplification of genetic material, nested-PCR was used. First reactions were performed with primers Em360F (5'-TTGGGTGTTGGTGTTGGTTGGACT-3') and Em1066R (5'-CCAGTAACACCACCAAACGT-3'), to second reaction primers Em590R (5'-ACGTTGCCTGTTTTGGCTGC-3') and Em900R (5'-CGTCTTCACATCCAACCCAACAG-3') were used to obtain a $310 \mathrm{bp}$ fragment of the mitochondrial cytochrome $c$ oxidase subunit 1 gene $(\operatorname{cox} 1)$. The reactions were conducted in a $40 \mu \mathrm{l}$ reaction mixture containing $2.0 \mu \mathrm{l}$ of DNA template, $0.2 \mu \mathrm{l}(1 \mathrm{U})$ of Color Taq DNA Polymerase (EURx, Poland), $1 \mu$ l of dNTPs mix (10mM), $0.5 \mu \mathrm{l}$ of each primer $(20 \mathrm{mM}), 5 \mu \mathrm{l}$ of $10 \times$ Polymerase buffer ( $\mathrm{pH} 8.6,25 \mathrm{mM} \mathrm{MgCl}$ ) and $30.8 \mu \mathrm{l}$ of MiliQ water. A negative control consisting of nuclease-free water was also added to the PCR mix instead of the tested DNA. DNA from adult E. multilocularis and cyst of E. granulosus s.l. (E. canadensis G7) were used as positive controls. DNA amplification was performed using the DNA Engine T100 Thermal Cycler (BioRad, USA) according to the following programme: denaturation at $95^{\circ} \mathrm{C} / 1 \mathrm{~min}$, followed by 34 cycles of denaturation at $95^{\circ} \mathrm{C} / 20 \mathrm{~s}$, annealing at $52^{\circ} \mathrm{C} / 20 \mathrm{~s}$ and extension at $72^{\circ} \mathrm{C} / 20 \mathrm{~s}$, with a final extension performed at $72^{\circ} \mathrm{C} / 3 \mathrm{~min}$. The PCR products were visualized on a $1.2 \%$ agarose gel (Promega, USA) stained with SimplySafe (EURx, Poland). Visualization was performed using ChemiDoc, MP Lab software (Imagine, BioRad, USA). The obtained PCR products were purified with QIAquick Gel Extraction Kit
(Qiagen, Germany). The purified products were sequenced directly using ABI BigDye ${ }^{\mathrm{m}}$ chemistry (Applied Biosystems, USA) on an ABI Prism 373xl or an ABI Prism $3100^{\text {th }}$ automated sequencer.

Echinococcus multilocularis (adults) and E. granulosus (one cyst from one patient) were used as positive controls to test the sensitivity of the PCR test. E. multilocularis four adult tapeworms, obtained as a result of the parasitological section of red foxes from near Łódź in Central Poland (unpublished data), from the collection of the Institute of Parasitology PAS. The sample of E. granulosus s.l. (E. canadensis, genotype G7) cyst was collected from the liver of a patient hospitalized in the Department of General Transplant and Liver Surgery at the Medical University in Warsaw [15]. E. multilocularis and E. granulosus s.l. cyst sequences of the cox 1 gene fragment were obtained (GenBanAaccession Nos.: E. multilocularis MT422809, MT423999, MT423998 and MT424001, E. granulosus s.l. (E. canadensis, G7) (MW271871).

Sensitivity of the test was validated with E. multilocularis DNA obtained from digesting the uterine segment of the tapeworm (containing about 300 eggs) [21]. DNA isolated from a single uterine member was suspended in $200 \mu \mathrm{l}$ of water. $1 \mu$ l of this DNA is sufficient to obtain the PCR reaction products, which corresponds to the amount of DNA obtained from $1.5 \mathrm{egg}$. In addition to testing the specificity of the designed primers, PCR reactions were carried out with DNA isolated from two species of tapeworms common in cats and dogs: Dipylidium caninum and Taenia taeniaeformis. No PCR products were obtained.

Molecular examination of faecal samples. Genomic DNA of taeniid tapeworms was extracted from faecal samples and

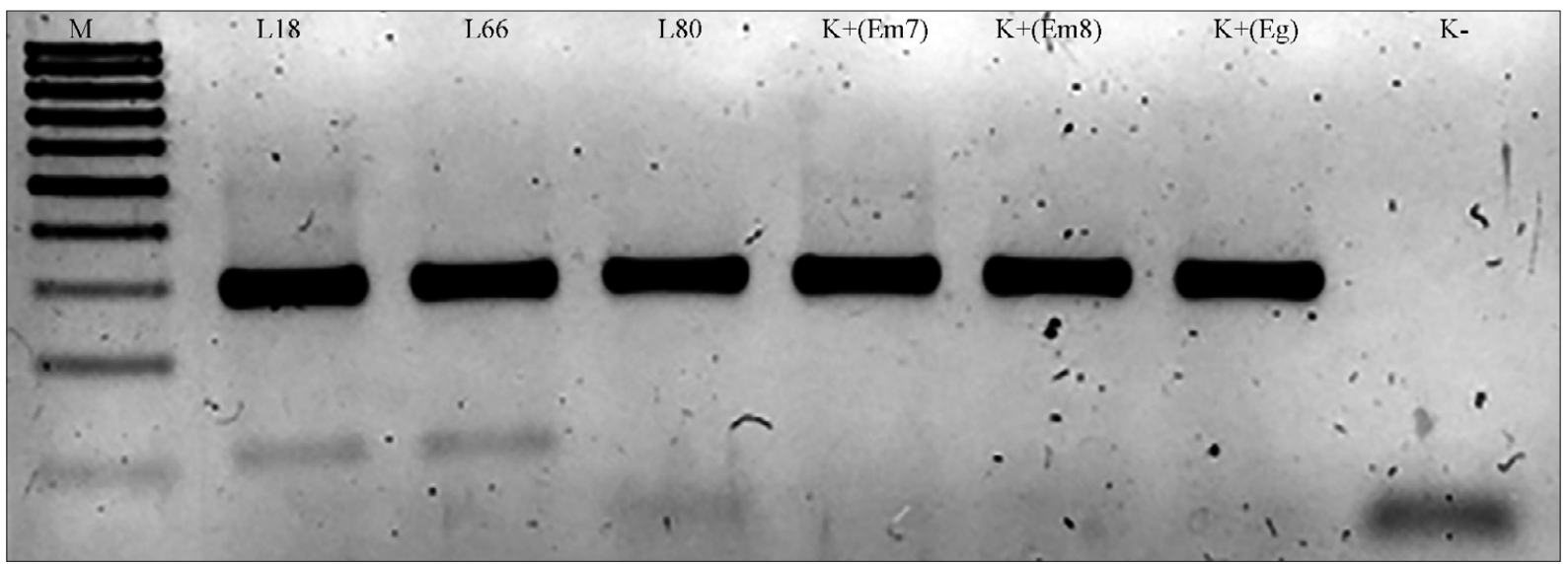

Figure 2. Gel with the results of the PCR reaction. $\mathrm{M}$ - 100bp ladder (Novazym), (L) - DNA from red fox faeces, (K+Em7) - DNA from adult E. multilocularis, (K+Em8) - DNA from adult E. multilocularis, (K+Eg) - DNA from cyst E. granulosus s.l., (K-) - Negative control (water)

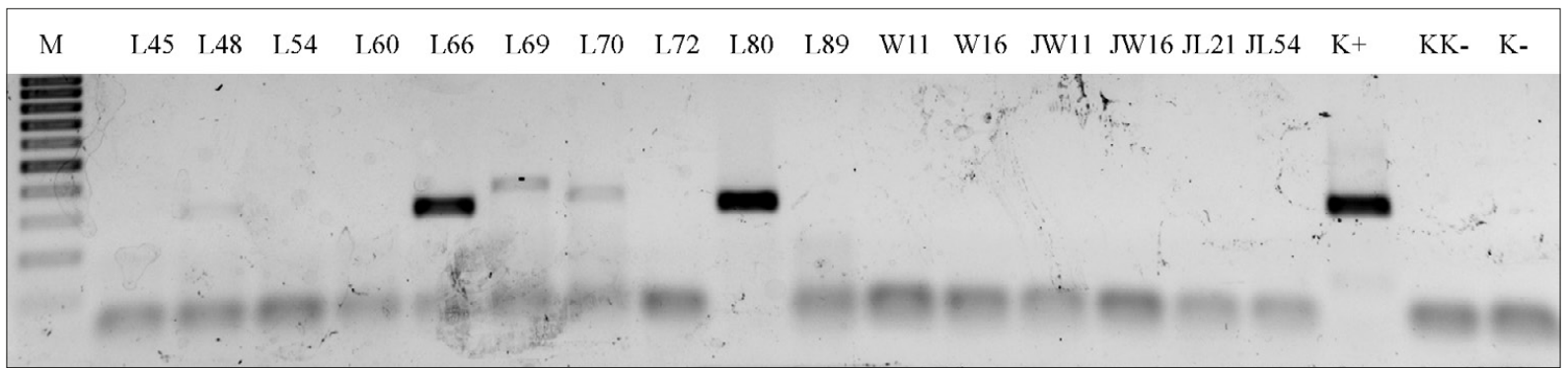

Figure 3. Sample photo of the gel with the results of the PCR reaction. $M$ - 100bp ladder (Novazym), (L) - DNA from red fox faeces, (W) - DNA from wolf faeces, (JL/JW) - DNA from eggs (flotation), (K+) - DNA from adult tapeworm, (KK-) - Negative control from first reaction (water) and (K-) - Negative control from second reaction (water) 
from taeniid eggs retrieved from the same faecal samples after flotation. The extraction was performed using Stool DNA Purification Kit (EURx, Poland), according to the manufacturer's instructions. Nested PCR described above was used for examination of DNA extracted from faecal samples. The results were compared with relevant sequences of Echinoccocus multilocularis and E. granulosus s.l. from red foxes and wolves from the GenBank database.

\section{RESULTS}

Flotation analysis. Based on the flotation analysis, among the 91 faecal samples from foxes, eleven (12.1\%) contained from 1 - 50 taeniid eggs (SEM 4.7), while among the 19 faecal samples from wolves, two were found positive (10.5\%) with two or 25 taeniid eggs recovered per 1 gram of faeces.

Molecular analysis. Among faecal samples from red foxes negative for taeniid egg by initial flotation, two (2.2\%) were found to be positive for E. multilocularis by using amplification with specific primers Em590F and Em900R. The PCR products obtained from both samples were purified and sequenced. The sequences (GenBank accession numbers: MT373716 and MT373727) obtained were identical to each other and to those obtained from adult E. multilocularis tapeworms (Fig. 2).

Taeniid eggs retrieved by flotation from 11 faecal samples from foxes were tested in the same way. The eggs from two samples were identified as E. multilocularis by the molecular assay. After all procedures, in 91 faecal samples from red fox, four were positive for E. multilocularis. No PCR products were obtained from wolf faeces with DNA directly isolated using a commercial kit, nor from taeniid eggs retrieved by initial flotation (Fig. 3).

\section{DISCUSSION}

The results are presented of a PCR assay for the occurrence of Echinococcus multilocularis and E. granulosus s.l in wild canids in the protected area of the Tatra National Park. Genomic DNA was obtained from taeniid eggs retrieved from faecal samples after flotation, and by direct extraction from the same samples using a commercial kit. For both Echinococcus species intended for testing, PCR primers based on Echinococcus multilocularis and E. granulosus s.s. G1 sequences were designed, and tested to amplify a part of the cox 1 mtDNA gen. For E. granulosus s.l., only one sample of one genotype, i.e. E. canadensis (G7) was used for molecular confirmation. Sequencing of the mitochondrial coxl gene allowed confirmation of E. multilocularis infection in four foxes (two samples directly from faeces, two from eggs retrieved after flotation). The nucleotide sequences of the cox 1 gene on the resulting $266 \mathrm{bp}$ fragment were $100 \%$ identical to each other. Comparison of these sequences with the deposited data allowed the conclusion that the haplotype obtained in the survey commonly occurs in red foxes in Poland [22]. Of the 15 haplotypes of E. multilocularis identified by Karamon et al. [22], on the analyzed fragment, 14 of them were consistent with the isolates obtained in the current survey. Analysis of the E. multilocularis cox 1 fragment in red foxes from the Tatra National Park allowed confirmation of this zoonotic tapeworm species. E. multilocularis with identical nucleotide sequence have been found in humans in Romania [23]. The obtained haplotype also commonly occurs among foxes in Europe: Slovakia - MN444796.1, Poland - MN444798.1, Hungary - JF747249.1 and France AB461413.1). The occurrence of this haplotype tapeworm has also been reported in dogs (Canis familiaris) in Canada [24] and in USA (LC380931.1), in rodents (water vole (Arvicola amphibious) in Germany (JF747248.1), and exotic animals (Senegal bushbaby (Galago senegalensis)) in Russia [25].

The occurrence of E. multilocularis in the fox population in the national park was predictable. The protected area is adjacent to a district established as being highly endemic for fox tapeworm, with a prevalence $63.9 \%$ [13]. In the province Lesser Poland, a mean of $20.1 \%-28.6 \%$ foxes were found to be infected $[13,14]$. To-date, no species specific survey for Echinococcus in wild canids has been undertaken in the protected area of the Tatra National Park. This study presents the first screening for Echinococcus multilocularis and E. granulosus s.l. based on faecal sample examination with molecular identification via a PCR assay in the fox and the wolf population. In a previous study in the protected area, taeniid eggs were recovered in $2.2 \%$ and $1.4 \%$ of faecal samples from 45 red foxes and 72 wolves, respectively, but no attempt was made for tapeworm species identification [26]. Necropsy study of 36 foxes shot in four municipalities in the vicinity of the current research site revealed the prevalence of E. multilocularis at $63.9 \%$ [13]. The probable reason for the much lower prevalence found in the present study is the faeces were collected from a population of foxes inhabiting mountain areas up to the alpine zone. They had limited access to rodents and the opportunity to feed on leftovers on hiking trails.

Investigations in Poland have shown a stable level of foxes infection in the regions with high prevalence of E. multilocularis $[3,27]$. In general, the extension of the E. multilocularis occurrence zone and increase in the parasite prevalence in red foxes have been observed in Europe during the last decades [7]. An example of the spread of this tapeworm is the finding in the Italian Maritime Alps in shepherd dogs and wolves [11], which is the southern-most report in Europe, apart from findings in foxes and golden jackals in Croatia and Serbia $[9,10,12]$. In the current study, fox faeces were collected in mountain areas, with some samples collected up to $2,000 \mathrm{~m}$ above sea level. The foxes roam the high mountains attracted by the accessibility of anthropogenic food sources. The current results have shown that humans might be exposed to a risk of fox tapeworm infection in nature, in an environment that seems clean from the point of view of parasitic threats.

Studies in the northern part of the Slovak Republic, the mountainous area adjacent to Tatra National Park, have shown the existence of a high-endemic focus for Echinococcus multilocularis with prevalence $39.1 \%-56.9 \%$ among a total of 1,138 red foxes investigated during $2001-2010$ [28, 29, 30].

In the current study no infection with E. granulosus s. 1. and E. multilocularis was detected in wolves based on the PCR assay with attempts to isolate DNA directly from 19 faecal samples. Taeniid eggs extracted from two faecal samples with flotation were also not confirmed as Echinococcus spp. Since only one sample of E. canadensis (G7) was tested as positive control, it was not possible to draw conclusions regarding the occurrence of other species and genotypes of E. granulosus s.l. in wolves in the Tatra National Park. The obtained results 
are similar to those from in the Slovakian part of the Tatra National Park, with no taeniid eggs detected in 79 faeces collected from wolves [31]. The majority of the Polish wolf population is a vital part of a larger, contiguous Eastern European wolf population, and the area of the Carpathian Mountains in the south-eastern part of Poland is the largest refuge for the wolves [32].

According to a genetic investigation conducted in 2017, fourteen unique wolf genotypes were found in the Tatra National Park [16]. Because their diet in the protected area consists mainly of medium to large-sized herbivores, such as red deer and roe deer [33], infection with Echinococcus granulosus s.l. might be expected. However, no studies have been conducted in Poland on the occurrence of Echinococcus spp. in wolves. Compared to E. multilocularis, epidemiological data on the frequency and distribution of E. granulosus s.l. in European wildlife is scarce, and to-date the wolf is the only wild carnivorous species identified as a definitive host of E. granulosus s.1. [34]. Sylvatic cycles of the parasite with the wolf involved have been documented in Finland [34], the Baltic countries [35, 36], Belarus [37] and in Italy in southern Europe [38]. Wolves are known to host E. multilocularis [39]. Based on a meta-analysis of the geographical distribution and prevalence of E. multilocularis in animals in 21 European countries, it was concluded that in areas with a high pooled prevalence of $E$. multilocularis in foxes, the wolf emerged as a potentially important definitive host [7]. Separate cases of the tapeworm infection in wolves have been documented in some countries: in Slovakia, E. multilocularis was detected in 9.7\% of samples of wolves' faeces among 31 samples examined [40]; in Latvia, the tapeworm was confirmed in $5.9 \%$ of 34 wolves hunted throughout the country [35]; in north-eastern France, known to be highly endemic for E. multilocularis with a prevalence in foxes estimated at $34 \%$, coprological analyses of potential definitive hosts in captivity (fox, lynx, wildcat, genet, wolf, bear and raccoon) revealed infection of E. multilocularis in one wolf [41]. In a study on Echinococcus granulosus s.l. infections in wolves and dogs in the Italian Maritime Alps, E. multilocularis eggs were confirmed in five out of 14 wolf fecal samples [11]. In the current study, due to the low number of secured samples and because the PCR was performed only one sample of E. canadensis (G7), no reliable assessment was possible of Echinococcus granulosus s.l. occurrence in wolves.

In areas endemic for E. multilocularis, veterinary staff should handle taeniid infections in canids based on egg detection as potential Echinococcus infections and a potential threat to humans. This recommendation is due to the fact that the eggs of Echinococcus spp. and Taenia spp. cannot be differentiated morphologically to the species level by microscopy after flotation [42].

\section{CONCLUSIONS}

The role of the wolf in the epidemiology of zoonotic parasitic agents needs further research. In contrast to foxes, long distance migration of wolves may be of importance for parasites transmission. The current results have shown that humans might be exposed to a risk of fox tapeworm infection in nature, even at high altitude in the alpine zone, in an environment contaminated by roaming foxes encouraged by food leftovers on mountain trails.

\section{Acknowledgements}

The authors would like to thank the staff of Tatra National Park, especially Jarosław Rabiasz and Józef Bobak for the collection of faecal samples. Research was partly financed from the resources of the Polish State Forests Forest Fund.

\section{REFERENCES}

1. Deplazes P, Rinaldi, L, Alvarez Rojas CA, et al. Global distribution of alveolar and cystic echinococcosis. Adv Parasitol. 2017; 95: 315-493. https://doi.org/10.1016/bs.apar.2016.11.001

2. Eckert J, Deplazes P. Biological, epidemiological, and clinical aspects of echinococcosis, a zoonosis of increasing concern. Clin Microbiol Rev. 2004; 17: 107-135. https://doi.org/10.1128/cmr.17.1.107-135.2004

3. Karamon J, Sroka J, Dąbrowska J, et al. First report of Echinococcus multilocularis in cats in Poland: a monitoring study in cats and dogs from a rural area and animal shelter in a highly endemic region. Parasit Vectors 2019; 12: 313. https://doi.org/10.1186/s13071-019-3573-x

4. Romig T, Dinkel A, Mackenstedt U. The present situation of echinococcosis in Europe. Parasitol Int. 2006; 55: 87-91. https:/doi. org/10.1016/j.parint.2005.11.028

5. Schweiger A, Ammann RW, Candinas D, et al. Human alveolar echinococcosis after fox population increase, Switzerland. Emerg Infect Dis. 2007; 13: 878-882. https://doi.org/10.3201/eid1306.061074

6. Combes B, Comte S, Raton V, et al. Westward spread of Echinococcus multilocularis in foxes, France, 2005-2010. Emerg Infect Dis. 2012; 18 : 2059-2062. https://doi.org/10.3201/eid1812.120219

7. Oksanen A, Siles-Lucas M, Karamon J, et al. The geographical distribution and prevalence of Echinococcus multilocularis in animals in the European Union and adjacent countries: a systematic review and meta-analysis. Parasit Vectors 2016; 9: 519. https:/doi.org/10.1186/ s13071-016-1746-4

8. Umhang G, Comte S, Hormaz, V, et al. Retrospective analyses of fox feces by real-time PCR to identify new endemic areas of Echinococcus multilocularis in France. Parasitol Res. 2016a; 115: 4437-4441. https:// doi.org/10.1007/s00436-016-5220-1

9. Beck R, Mihaljević Ž, Brezak R, et al. First detection of Echinococcus multilocularis in Croatia. Parasitol Res. 2018; 117: 617-621. https://doi. org/10.1007/s00436-017-5732-3

10. Lalošević D, Lalošević V, Simin V, et al. Spreading of multilocular echinococcosis in southern Europe: the first record in foxes and jackals in Serbia, Vojvodina Province. Eur J Wildl Res. 2016; 62: 793-796. https://doi.org/10.1007/s10344-016-1050-9

11. Massolo A, Valli D, Wassermann M, et al. Unexpected Echinococcus multilocularis infections in shepherd dogs and wolves in south-western Italian Alps: A new endemic area? Int J Parasitol Parasites Wildl. 2018; 7: 309-316. https://doi.org/10.1016/j.ijppaw.2018.08.001

12. Sindičić M, Bujanić M, Štimac I, et al. Identification of Echinococcus multilocularis in golden jackals in Croatia. Acta Parasitol. 2018; 63: 654-656. https://doi.org/10.1515/ap-2018-0076

13. Borecka A, Gawor J, Malczewska M, et al. Occurrence of Echinococcus multilocularis in red foxes (Vulpes vulpes) in southern Poland. Helminthologia 2008; 45: 24-27. https://doi.org/10.2478/s11687-0080004-5

14. Karamon J, Kochanowski M, Sroka J, et al. The prevalence of Echinococcus multilocularis in red foxes in Poland - current results (2009-2013). Parasitol Res. 2014; 113: 317-322. https://doi.org/10.1007/ s00436-013-3657-z

15. Sałamatin R, Kowal J, Nosal P, et al. Cystic echinococcosis in Poland: genetic variability and the first record of Echinococcus granulosus sensu stricto (G1 genotype) in the country. Parasitol Res. 2017; 116: 3077-3085. https://doi.org/10.1007/s00436-017-5618-4

16. Mysłajek RW, Szewczyk M, Zwijacz-Kozica T, et al. Genetic diversity in wolf Canis lupus population in Tatra Mountains. Studia i Materiały CEPL w Rogowie 2019; 59: 38-45.

17. Zwijacz-Kozica T. Animals of Tatra National Park in 2017 (in Polish). Wierchy 2020; 83: 194-202.

18. Cichocki J, Ważna A, Janik-Superson $\mathrm{K}$, et al. The impact of red fox Vulpes vulpes depredation on the populations of protected and endangered species in the Tatra National Park (in Polish). 2019. https:// erebia.tpn.pl/share.cgi?ssid=0gVKkBe. Accessed 7 September 2020.

19. Veit P, Bilger B, Schad V, et al. Influence of environmental factors on the infectivity of Echinococcus multilocularis eggs. Parasitology 1995; 110: 79-86. https://doi.org/10.1017/s0031182000081075 
20. Ballweber LR, Beugne F, Marchiondo AA, et al. American Association of Veterinary Parasitologists' review of veterinary fecal flotation methods and factors influencing their accuracy and use-Is there really one best technique? Vet Parasitol. 2014; 204: 73-80. http://dx.doi.org/10.1016/j. vetpar.2014.05.009

21. Alvarez Rojas CA, Mathis A, Deplazes P. Assessing the contamination of food and the environment with Taenia and Echinococcus eggs and their zoonotic transmission. Curr Clin Microbiol Rep. 2018; 5: 154-163. https://doi.org/10.1007/s40588-018-0091-0

22. Karamon J, Stojecki K, Samorek-Pieróg M, et al. Genetic diversity of Echinococcus multilocularis in red foxes in Poland: the first report of a haplotype of probable Asian origin. Folia Parasitol. 2017; 64: 007. https://doi.org/10.14411/fp.2017.007

23. Šnabel V, Calma C, Georgescu SO, et al. Genetic survey of alveolar and cystic echinococcoses in Romania: First molecular evidence of Echinococcus multilocularis in humans in the country. Helminthologia 2017; 54: 189-198. https://doi.org/10.1515/helm-2017-0025

24. Gesy KM, Jenkins EJ. Introduced and native haplotypes of Echinococcus multilocularis in wildlife in Saskatchewan, Canada. J Wildl Dis. 2015; 51: 743-748. https://doi.org/10.7589/2014-08-214

25. Konyaev SV, Yanagida T, Nakao M, et al. Genetic diversity of Echinococcus spp. in Russia. Parasitology 2013; 140: 1637-1647. https:// doi.org/10.1017/S0031182013001340

26. Borecka A, Gawor J, Zięba F. A survey of intestinal helminths in wild carnivores from the Tatra National Park, southern Poland. Ann Parasitol. 2013; 59: 169-172. PMID: 24791342

27. Karamon J, Kochanowski M, Dabrowska J, et al. Dynamics of Echinococcus multilocularis infection in red fox populations with high and low prevalence of this parasite in Poland (2007-2014) Bull Vet Inst Pulawy 2015; 59: 213-217. https://doi.org/10.1515/bvip-2015-0032

28. Miterpáková $\mathrm{M}$, Dubinský $\mathrm{P}$, Reiterová $\mathrm{K}$, et al. Climate and environmental factors influencing Echinococcus multilocularis occurrence in the Slovak Republic. Ann Agric Environ Med. 2006; 13: 235-242. PMID: 17195995

29. Miterpáková M, Dubinský P. Fox tapeworm (Echinococcus multilocularis) in Slovakia - summarizing the long-term monitoring. Helminthologia 2011; 48: 155-161. https://doi.org/10.2478/s11687-0110023-5
30. Hurníková Z, Miterpáková M, Čabanová V, et al. Free-living carnivores as an important reservoir of zoonotic parasites in the Tatra Mountains region, Slovakia. Ann Parasitol. 2016; Supl, 62, 21.

31. Čabanová V, Guimaraes N, Hurníková Z, et al. Endoparasites of the grey wolf (Canis lupus) in protected areas of Slovakia. Ann Parasitol. 2017; 63: 283-289. https://doi.org/10.17420/ap6304.114

32. Bień J, Moskwa B, Goździk K, et al. The occurrence of nematodes of the genus Trichinella in wolves (Canis lupus) from the Bieszczady Mountains and Augustowska Forest in Poland. Vet Parasitol. 2016; 15: 115-117. https://doi.org/10.1016/j.vetpar.2016.04.010

33. Cichocki J. Composition of gray wolf (Canis lupus) diet in the Tatra National Park. Reports of the Tatra National Park (in Polish). 2019. https://erebia.tpn.pl/share.cgi?ssid=0kXvtPj. Accessed 22 November 2019.

34. Hirvelä-Koski V, Haukisalmi V, Kilpelä S, et al. Echinococcus granulosus in Finland. Vet Parasitol. 2003; 111: 175-92. https://doi. org/10.1016/S0304-4017(02)00381-3

35. Bagrade G, Kirjušina M, Vismanis K, et al. Helminth parasites of the wolf Canis lupus from Latvia. J Helminthol. 2009; 83: 63-68. https:// doi.org/10.1017/S0022149X08123860

36. Moks E, Jögisalu I, Saarma U, et al. Helminthologic survey of the wolf (Canis lupus) in Estonia, with an emphasis on Echinococcus granulosus. J Wildl Dis. 2006; 42: 359-365. https://doi.org/10.7589/0090-355842.2.359

37. Shimalov VV, Shimalov VT. Helminth fauna of the wolf (Canis lupus Linnaeus, 1758) in Belorussian Polesie. Parasitol Res. 2000; 86: 163-164. https://doi.org/10.1007/s004360050026

38. Guberti V, Bolognini M, Lanfranchi P, et al. Echinococcus granulosus in the wolf in Italy. Parassitologia 2004; 46: 425-427. PMID: 16044708

39. Romig T, Deplazes P, Jenkins D, et al. Chapter five - Ecology and life cycle patterns of Echinococcus species. Adv Parasitol. 2017; 95: 213-314. https://doi.org/10.1016/bs.apar.2016.11.002

40. Martinek K, Kolařova L, Hapl E, et al. Echinococcus multilocularis in European wolves (Canis lupus). Parasitol Res. 2001; 87: 838-839. https://doi.org/10.1007/s004360100452

41. Umhang G, Lahoreau J, Hormaz V, et al. Surveillance and management of Echinococcus multilocularis in a wildlife park. Parasitol Int. 2016b; 65: 245-250. https://doi.org/10.1016/j.parint.2016.01.008

42. ESCCAP Guideline 01 Worm control in dogs and cats. 2020, sixth Edition, pp 42. https://www.esccap.org/guidelines/gl1/ 